\title{
Lambda Red-mediated Recombineering in the Attaching and Effacing Pathogen Escherichia albertii
}

\author{
Marisa Egan ${ }^{1,2}$, Jasmine Ramirez ${ }^{1,5}$, Christian Xander ${ }^{1,6}$, Chirag Upreti $^{3,4}$ and Shantanu Bhatt ${ }^{1 *}$
}

\begin{abstract}
Background: The ability to introduce site-specific mutations in bacterial pathogens is essential towards understanding their molecular mechanisms of pathogenicity. This has been greatly facilitated by the genetic engineering technique of recombineering. In recombineering, linear double- or single-stranded DNA molecules with two terminal homology arms are electroporated into hyperrecombinogenic bacteria that express a phage-encoded recombinase. The recombinase catalyzes the replacement of the endogenous allele with the exogenous allele to generate selectable or screenable recombinants. In particular, lambda red recombinase has been instrumental in engineering mutations to characterize the virulence arsenal of the attaching and effacing (A/E) pathogens enteropathogenic Escherichia coli (EPEC), enterohemorrhagic E. coli (EHEC), and Citrobacter rodentium. Escherichia albertii is another member of this taxon; however, the virulence of $E$. albertii remains cryptic despite accumulating evidence that $E$. albertii is an emerging pathogen. Multiple retrospective studies have reported that a substantial number of EPEC and EHEC isolates ( $15 \%)$ that were previously incriminated in human outbreaks actually belong to the E. albertii lineage. Thus, there is increased urgency to reliably identify and rapidly engineer mutations in E. albertii to systematically characterize its virulence determinants. To the best of our knowledge not a single chromosomal gene has been altered by targeted mutagenesis in E. albertii since it was first isolated almost 25 years ago. This is disconcerting because an E. albertii outbreak could cause significant morbidity and mortality owing to our inadequate understanding of its virulence program.
\end{abstract}

Results: In this report we describe a modified lambda red recombineering protocol to mutagenize E. albertii. As proof of principle, we successfully deleted three distinct virulence-associated genetic loci - ler, grlRA, and hfq - and replaced each wild type allele by a mutant allele with an encodable drug resistance cassette bracketed by FRT sites. Subsequently, the FRT-site flanked drug resistance marker was evicted by FLP-dependent site-specific recombination to generate excisants containing a solitary FRT site.

Conclusions: Our protocol will enable researchers to construct marked and unmarked genome-wide mutations in E. albertii, which, in turn, will illuminate its molecular mechanisms of pathogenicity and aid in developing appropriate preventative and therapeutic approaches to combat $E$. albertii outbreaks.

Keywords: Exo, Bet, Gam, Recombineering, LEE, Escherichia albertii

\footnotetext{
* Correspondence: sbhatt@sju.edu

'Department of Biology, Saint Joseph's University, 5600 City Avenue,

Philadelphia, PA 19131, USA

Full list of author information is available at the end of the article
} 


\section{Background}

Whole genome sequencing has ushered in a new era that has revolutionized the field of microbial genetics $[1,2]$. Within the past decade sequencing has become more robust, inexpensive, and quick. A scientific sub-discipline that has benefited immensely from rapid genome sequencing is bacterial pathogenesis [3, 4]. The availability of complete genome sequences has enabled bacteriologists to undertake a global investigation of a pathogen's transcriptome [5-8], proteome [9-11], and metabolome $[12,13]$ at an unprecedented level. However, the accumulation of such large-scale genome-wide data has left scientists with even more questions than answers $[1,2]$. For instance, in any sequenced microbial genome a substantial number of genes remain functionally unannotated or classified as "putative" or "hypothetical" [1, 2]. Similarly, transcriptomic, proteomic, and metabolomic studies, while highlighting the number and nature of specific biomolecules expressed under specific conditions, do not reveal their function [1]. Thus, now, more than ever before, the tools and techniques used in forward (starting from a biological process and determining its genetic basis) and reverse genetics (starting from a gene and determining the biological process(es) controlled by it) will become invaluable and essential towards understanding the functions of genes on a genome-wide scale.

The single most important technique in the molecular toolkit of a microbial geneticist is mutagenesis. Mutagenesis enables a researcher to construct mutations - stable changes in the nucleotide sequence of an organism that are inheritable. Analysis of mutants, in turn, permits researchers to characterize the environmental and regulatory controls of a gene $[14,15]$, deduce the structurefunction relationship of the gene product [16, 17], and determine the regulon and range of biological processes controlled by it [18-20]. Mutations can be classified on the basis of the effect that they have on the expression and/or activity of the gene product. The different kinds of mutations include amorphic (complete loss in expression and/or activity of the gene product), hypomorphic (reduced expression and/or activity), hypermorphic (increased expression and/or activity), neomorphic (a novel function or pattern of expression associated with the gene product), and antimorphic (dominant negative) mutations. To introduce such mutations in bacterial genomes geneticists have developed a diverse range of chemical, biological, and physical mutagens [1]. Some of these mutagens such as base analogues, alkylating agents, radiations, and transposable elements introduce nonspecific and genome-wide random mutations $[1,2]$. By contrast, the construction of gene-specific mutations is primarily accomplished by the use of suicide vectors $[2,21,22]$ or recombineering [23-32].
A suicide vector is a plasmid that possesses certain key characteristics: a conditional origin of replication that enables the plasmid to replicate under permissive conditions but not under non-permissive conditions, a selectable maker, which confers a phenotypic benefit to the bacterium under specific conditions (e.g. drug resistance or prototrophy), a counterselectable marker, which promotes bacterial death under certain conditions (e.g. an enzyme that converts a pro-drug to a drug toxic to the bacterium), and a polylinker region to facilitate cloning $[2,21,22,33]$. The desired mutant allele is inserted into the polylinker region and the recombinant vector is introduced into a suitable bacterial transcipient. The transcipient is subsequently grown under conditions that are not only non-permissive for plasmid replication but also select for bacteria that stably express the plasmidencoded selectable trait. The mutant colonies that are observed are merodiploid integrants, in which the plasmid encoded mutant allele has undergone homologous recombination with the chromosomally encoded wild type allele thereby inserting the entire plasmid into the bacterial chromosome and facilitating the expression of the selectable marker. Integrants can then be grown under conditions where the counterselectable marker is expressed to induce toxicity and promote bacterial lethality. Any observed excisants are typically those in which the counterselectable marker, along with the plasmid backbone, has been successfully evicted. This occurs by a second recombinational event between the wild type and mutant allele, which either restores the original wild type allele or replaces it with the mutant allele $[2,21,22]$. Suicide vectors can be used to introduce a gamut of precise chromosomal modifications in different bacteria [34-38]. However, in today's day and age of genetic engineering the reliance on suicide vectors to introduce gene-specific mutations has diminished substantially. This is because this technique is cumbersome, requires prior cloning of the mutant allele onto the suicide vector, is limited by the presence of restriction sites on the plasmid, prone to illegitimate recombinational events, and logistically may span several days.

Within the past decade the revolutionary technique of recombineering has largely replaced the use of suicide vectors to construct locus specific mutations [23, 25-28, 31, 32, 39-41]. Recombineering circumvents the need to rely on restriction enzymes, DNA ligases, and cloning into suicide vectors for allelic replacement. Recombineering, a portmanteau for recombination-mediated genetic engineering, is a technique for manipulating the bacterial genome in vivo by using phage-encoded recombinases [31]. The most frequently employed recombinases include the Rac prophage-encode RecET [32, 42-44] and the lambda prophage-encoded Red [23-28, 31, 41]. Bacteria that express RecET or lambda Red proteins are 
rendered hyperrecombinogenic and are capable of catalyzing efficient homologous recombination between linear single-stranded (ss) or double-stranded (ds) DNA molecules with two short terminal arms that share $~ 40-50$ nucleotides of homology to a target DNA [23-26, 32, 40, 45]. The RecET system consists of two proteins - RecE and RecT [32]. RecE is a ds specific DNA exonuclease that sequentially degrades the $5^{\prime}$ end of DNA to generate single stranded (ss) 3' overhangs [42]. RecT, in turn, binds to the ssDNA and facilitates base pairing between the two homology arms and complementary sequences on the target DNA resulting in homologous recombination and the eventual replacement of the chromosomal allele with the mutant allele [32, 44]. The lambda Red recombination system includes three proteins - Exo, Beta, and Gam [23, 26, 27, 31, 41]. Exo, like RecE, is a $5^{\prime} \rightarrow 3^{\prime}$ dsDNA specific exonuclease that generates a ssDNA intermediate $[39,46]$. Beta, like RecT, binds to the ssDNA intermediate and base pairs it to its complementary single stranded target to form a heteroduplex and facilitate homologous recombination $[47,48]$. An accessory component of the lambda red system is Gam. Gam inhibits the RecBCD and SbcCD nucleases thereby preventing the degradation of dsDNA to enhance recombination $[49,50]$. When linear dsDNA is used as a substrate then both the exonuclease (RecE/Exo) as well as the ssDNA binding protein (RecT/Bet) are necessary for recombineering $[29,51]$. By contrast, when ssDNA/oligonucleotides are used, then the ssDNA anealing protein is sufficient for homologous recombination $[40,52,53]$. Furthermore, recombination frequencies are orders of magnitude higher using ssDNA compared to dsDNA [29].

The lambda Red recombineering system, in particular, has transformed our understanding of the molecular mechanisms of bacterial pathogenicity in a wide range of Gram-negative pathogens including several members of the attaching and effacing (A/E) family of pathogens, which encompasses enteropathogenic Escherichia coli (EPEC), enterohemorrhagic E. coli (EHEC), Citrobacter rodentium, and Escherichia albertii [14, 15, 25, 35, 37, 54]. A/E pathogens are classified as such because upon infection the bacterium depolymerizes actin filaments, thereby destroying the structural and functional integrity of the intestinal microvilli (effacement) $[14,15,55,56]$. Thereafter, the depolymerized actin is recruited beneath the adherent bacterium and repolymerized to form actin-filled membraneenclosed evaginations called pedestals that are capped by the infecting bacterium (attachment) $[14,15,56,57]$. The overall pathological manifestation of attachment and effacement is the diminished ability of enterocytes to absorb water and nutrients, which leads to diarrhea $[14,15]$.

The pathogenicity island locus of enterocyte effacement (LEE) is essential for pedestal formation [14, 15, 58-61].
The LEE encodes a functional type 3-secretion system (T3SS) that punctures the host cell membrane and allows A/E pathogens to inject a range of effector molecules directly into the infected cell [37, 62-69]. These effector molecules are involved in the subversion of host signal transduction and regulatory pathways, which lead to the observed ultrastructural changes including microvillar disintegration and pedestal formation - diagnostic hallmarks of infection by the A/E pathogens $[14,15]$. Thus, understanding the regulation of the LEE is imperative to develop efficacious prophylactic and/or therapeutic measures. Between EPEC and EHEC virtually every conceivable mutation - point, substitutions, insertions, deletions, epitope tagging, and marked- has been engineered by recombineering $[25,35,70-72]$. This constellation of mutations has revealed an intricate regulatory landscape that fine-tunes gene expression from the LEE in response to diverse environmental stimuli [14, 15, 73]. Moreover, recombineered EPEC and EHEC mutants have also yielded mechanistic insight into several trans-acting factors and cis-acting elements [14, 15, 74]. Similarly, in the murine pathogen Citrobacter rodentium recombineering was used, in part, to systematically mutate every gene that is encoded within the LEE to elucidate the genetic control of pathogenesis [37]. This study was groundbreaking in that the researchers identified two novel LEE-encoded regulators, GrlR and GrlA, that repress and activate the LEE respectively [37]. Besides GrlR and GrlA, the LEE also encodes the master transcriptional regulator, Ler $[75,76]$. Ler, GrlR, and GrlA are conserved between Citrobacter rodentium, EPEC, and EHEC [14, 15, 37, 73, 75, 76]. These transcription factors are indispensible for the synchronized spatiotemporal regulation of genes expression from the LEE, which climaxes with pedestal morphogenesis and the accompanying virulence of $\mathrm{A} / \mathrm{E}$ pathogens $[14,15]$. Intriguingly, even though the lambda red proteins are operational in A/E pathogens, induction of a hyperrecombinogenic state depends upon the vector that expresses these genes. For instance, Murphy and Campellone observed that EHEC recombinants are readily obtainable only when the lambda red genes were expressed from the low-copy plasmids pKM201 or pKM208 but not when the expression platform was the high-copy plasmid pTP223 [25]. Reciprocally, in EPEC, recombinants were only observed when the lambda red proteins were expressed from pTP223 [25]. Similar observations have also been reported in E. coli [23]. Thus, the expression of lambda red proteins from a suitable vector is instrumental in engineering defined mutations in bacteria.

Whereas recombineering has been effectively utilized to understand the molecular pathogenesis of EPEC, EHEC, and Citrobacter rodentium, it has, thus far, not been adapted for Escherichia albertii [25, 35, 37, 54, 77, 78]. E. albertii was first isolated from diarrheal stool 
samples of five children from Bangladesh by John Albert and his collaborators at the International Centre for Diarrheal Disease Research, Bangladesh (ICDDR-B) in the early 1990s [79]. The children were febrile, presenting with watery diarrhea, dehydration, vomiting, and abdominal distension. Initially, these isolates were classified as Hafnia alvei [79]. However, Albert et al. subsequently discovered that these isolates possessed the eae gene, which is normally present in $\mathrm{A} / \mathrm{E}$ pathogens but absent in $H$. alvei. eae codes for intimin - an outer membrane protein essential for pedestal formation by A/E pathogens [80]. Moreover, a comparison of the 16S rRNA sequence of these strains with eae-negative $H$. alvei isolates revealed a low degree of sequence similarity, thereby warranting their taxonomic reclassification [81]. Subsequent attempts to accurately reclassify these diarrheal isolates also yielded ambiguous results [82]. The same isolates yielded highly variable phenotypic and biochemical profiles characteristic of Yersinia ruckeri, Salmonella enterica, H. alvei, EHEC, and Citrobacter depending upon the commercial diagnostic kit used for taxonomic classification [82]. More recently though, using a battery of conventional biochemical and phenotypic assays, 16S rRNA sequencing, DNA-DNA hybridization, and allele-specific PCR these isolates were unambiguously shown to be distantly related to the Escherichia (55-64 \%) and Shigella (54-60 \%) genera and have been defined as a novel Escherichia species, Escherichia albertii [82, 83]. Still, very little is known about this diarrheal pathogen today, so its misidentification persists. A recent retrospective study reexamined 179 clinical strains that were originally isolated from diseased humans and animals and had been classified as EPEC or EHEC on the basis of routine diagnostic assays. Multilocus sequencing of these strains revealed that of these strains, 26 (14.5\%) were actually E. albertii isolates that had been incorrectly assigned to the EPEC or EHEC taxa [84]. Similarly, EPEC was implicated as the etiologic agent for a foodborne outbreak in Fukuoka and Kumamoto cities of Japan in 2003 and 2011 respectively. However, reexamination of these strains by PCR and additional biochemical assays confirmed them to belong to the $E$. albertii lineage $[85,86]$. In another recent study an $E$. albertii strain possessing the $s t x_{2 a}$ allele was isolated from a patient who suffered from bloody diarrhea in Norway [87]. Shiga toxin 2a (Stx2a) is one of the most potent isoforms of the Shiga toxin that has been implicated in hemorrhagic colitis and the life-threatening complication hemolytic uremic syndrome (HUS) [88-91]. Prior to this report, only the $s t x_{2 f}$ allele, which produces mild symptoms and has no prior link to bloody diarrhea or HUS, was reportedly observed in a subset of E. albertii strains [84, 87]. In the genus Escherichia stx2a is most frequently associated with EHEC [92], and to a lesser degree with enteroaggregative E. coli (EAEC) [93]. This presence of this allelic variant has often been used as a reliable marker to narrow down the Escherichia isolate to these pathotypes. However, the presence of $s x_{2 a}$ in $E$. albertii suggests that some of $s_{2} x_{2 a}$ possessing $E$. coli strains that are currently designated as EHEC or EAEC may actually be E. albertii. Moreover, this genotypic feature accentuates the virulence potential of $E$. albertii. Clearly, there is increased urgency to reliably diagnose $E$. albertii isolates and rapidly identify and characterize the repertoire of its virulence determinants, determine their mode of action, and the virulence-associated processes controlled by them - a formidable task that requires the engineering of specific and random $E$. albertii mutants.

While the genome of $E$. albertii has been sequenced, to the best of our knowledge, we have not encountered any reports demonstrating chromosomal modifications in $E$. albertii. Here we describe a simple modified protocol using the lambda Red recombineering system to generate chromosomal mutations in $E$. albertii, which appears to be genetically recalcitrant. Using this protocol we successfully deleted the LEE-encoded genes, ler and $\operatorname{grl} R A$, and the non-LEE encoded gene $h f q$, albeit at frequencies lower than those reported in E. coli. This protocol will aid pathogeneticists to rapidly construct knockout, knockin, epitope-tagged, transcriptional, translational, and other subtle mutations in E. albertii in order to comprehensively characterize its molecular mechanisms of virulence to successfully counteract this emerging broad host pathogen.

\section{Results and Discussion}

Our initial attempts at recombineering in E. albertii using pKD46 were largely unsuccessful or non-reproducible (data not shown). Previous research has shown that recombineering efficiency is significantly enhanced in the related bacterium $E$. coli when the lambda red genes are expressed from the pSIM rather than the pKD family of plasmids [28]. The pSIM family of plasmids is derived from the defective lambda prophage in which the minimal lambda red recombinase operon, consisting of the genes gam, bet, and exo, is expressed from the $p_{L}$ promoter under the transcriptional control of the thermolabile CI857 lambda repressor [28]. At low temperatures ranging from $30-34{ }^{\circ} \mathrm{C}$ CI857 is active and binds to the operator site thereby sterically hindering the promoter and preventing transcription. A thermal upshift to $42{ }^{\circ} \mathrm{C}$ reversibly denatures the $\mathrm{CI} 857$ repressor thereby inactivating it and leading to the derepression of the gam, bet, and exo genes thereby inducing a temporary hyperrecombinogenic state in the bacterium [28]. When such a bacterium is transformed with dsDNA or oligonucleotides that possess two terminal arms of $\sim 40-50$ nucleotides of homology to a target gene the lambda red recombinase promotes the 
replacement of the endogenous allele with the exogenous allele. Transcription from $p_{L}$ promoter can be shut off by transferring the cultures back to $30{ }^{\circ} \mathrm{C}$ at which the CI857 repressor renatures and binds to the operator to prevent further transcription. Reversible repression by CI857 prevents the unregulated expression of the lambda red genes, which has previously been shown to be mutagenic [25].

Induction of the lambda red genes for as little as 15 min generates a large number of recombinants in $E$. coli. We used conditions similar to those previously described for $E$. coli to engineer hyperrecombinogenicity in E. albertii. LS5504 (E. albertii strain Albert $19982^{\mathrm{T}}$ transformed with pSIM6) was thermally induced for 7.5, 15 , or $30 \mathrm{~min}$ at $42{ }^{\circ} \mathrm{C}$ and subsequently made electrocompetent. Electrocompetent cells were then transformed with $1.5 \mu \mathrm{g}$ of $\Delta l e r:: c a t$ amplicon at $1.8 \mathrm{kV}$. After overnight recovery cultures were spread on LB plates supplemented with chloramphenicol $(3.125 \mu \mathrm{g} / \mathrm{ml})$ and screened to identify $\mathrm{Cm}^{\mathrm{R}}$ recombinants. No recombinants were obtained under these experimental conditions. Interestingly, when the electroporation voltage was increased to $2.5 \mathrm{kV}$, a reproducible increase in recombineering was observed with $\sim 14.0 \pm 1.3$ recombinants per $10^{10} \mathrm{cfu}$ per $\mu \mathrm{g}$ of DNA. Recombinants were observed at chloramphenicol concentrations as high as $6.25 \mu \mathrm{g} / \mathrm{ml}$ (data not shown). At higher concentrations $(12.5-25 \mu \mathrm{g} / \mathrm{ml})$ no recombinants were observed. Interestingly, the higher concentrations correspond to the selective conditions typically used by us to isolate recombinants of EPEC and E. coli (data not shown). Thereafter, we proceeded to vary other experimental parameters to further enhance recombineering efficiency. We reasoned that prolonged expression of the lambda red genes could further increase recombineering. Consistent with this prediction induction of the red operon for an hour at $42{ }^{\circ} \mathrm{C}$ followed by electroporation at $2.5 \mathrm{kV}$ further increased the recombination frequency by $\sim 3.3$-fold $\left(46.2 \pm 7.3\right.$ recombinants per $10^{10} \mathrm{CFU}$ per $\mu \mathrm{g}$ of DNA). From one such experiment $12 \mathrm{Cm}^{\mathrm{R}}$ mutants were screened by locus specific PCR to verify that the $\mathrm{Cm}^{\mathrm{R}}$ phenotype stemmed from the allelic replacement of ler $^{+}$with the $\Delta$ ler::cat allele (Fig. 1a). Of the 12 isolates screened, 11 had successfully replaced the wild type allele with the mutant allele (Fig. 1a). pSIM6 was cured from the recombinants by culturing them at $42^{\circ} \mathrm{C}$.

We then proceeded to test the feasibility of evicting the cat cassette that is bracketed by direct repetitive FRT sites. Two such Aler::cat mutants (LS5568 \& LS5570) were transformed with the plasmid pFT-K, which expresses FLP recombinase under the control of the TetR repressor, to generate LS5592 and LS5593 respectively. Unautoclaved chlorotetracycline was added at a range of concentrations $(20-200 \mu \mathrm{g} / \mathrm{ml})$ to inactivate TetR to derepress FLP recombinase. FLP recombinase catalyzes the site-specific recombination between the two FRT sites to evict the cat cassette and generate excisants that are phenotypically $\mathrm{Cm}^{\mathrm{S}}$ and contain a single FRT site. It was observed that the excision frequency decreased precipitously as the concentration of chlorotetracycline increased (Fig. 1b). At a chlorotetracycline concentration of $20 \mu \mathrm{g} / \mathrm{ml} \sim 90 \%$ of the observed colonies had evicted the cat cassette, whereas at $200 \mu \mathrm{g} / \mathrm{ml}$ the eviction frequency was reduced to $\sim 15 \%$ (Fig. 1b). This was unexpected because we anticipated that increasing the chlorotetracycline concentration would lead to higher expressivity of $f l p$ and enhance excision frequency. However, we did observe that as the chlorotetracycline concentration was increased the total CFU count decreased substantially (data not shown). Perhaps, the slowed growth rate may detrimentally affect the expression and/or activity of the FLP recombinase enzyme. $\mathrm{Cm}^{\mathrm{S}}$ excisants were also verified by locus specific PCR to confirm that the sensitivity to the antibiotic correlated with the loss of the cat cassette and the presence of the $\Delta$ ler::FRT allele (Fig. 1c). pFT-K was successfully cured from the excisants by incubating them at $42{ }^{\circ} \mathrm{C}$ overnight and screening for $\mathrm{Kan}^{\mathrm{S}}$ isolates (data not shown).

The usefulness of lambda red recombineering arises from the fact that it can be utilized to engineer a plethora of mutations at virtually any genetic loci in a range of bacteria [23-26, 37]. Therefore, we next determined if recombineering was equally versatile in $E$. albertii. To address this we attempted to mutate the $\operatorname{grlRA}$ operon, located within the LEE, and the $h f q$ gene, located outside the LEE. The LEE-encoded $\operatorname{grlRA}$ locus specifies the two transcription factors GrlR and GrlA that exhibit conserved synteny in all the $\mathrm{A} / \mathrm{E}$ pathogens including $E$. albertii [37, 94-97]. GrlR and GrlA synchronize gene expression from the LEE that culminates with pedestal morphogenesis by EPEC, EHEC, and Citrobacter rodentium [14, 15, 37, 70, 98]. Meanwhile, Hfq functions as an RNA chaperone that facilitates base-pairing between sRNAs and their target mRNAs to affect RNA stability and/or translation $[99,100]$. Hfq has a prominent role in controlling the LEE in EPEC and EHEC [18, 19, 94] (Bhatt S. Unpublished observations). However, the roles of $g r l R$, grlA, and $h f q$ remain unexplored in E. albertii. The $\triangle g r l R A:: k a n$ and $\triangle h f q:: c a t$ mutant alleles were synthesized by PCR essentially as described above. The $\triangle \operatorname{grlRA}:: k a n$ amplicon possesses two terminal homology arms of 50 nucleotides in length. The upstream arm is identical to the region immediately upstream of the $g r l R$ ORF whereas the downstream arm is identical to the 3' end of the grlA ORF (30 nucleotides) and 20 nucleotides downstream off of it. Thus, upon successful recombineering, the entire grlRA operon excluding the terminal 30 nucleotides of the grlA ORF and its 3' UTR are replaced by a kan cassette bracketed by FRT sites. The $\Delta g r l R A:: k a n$ amplicon was 


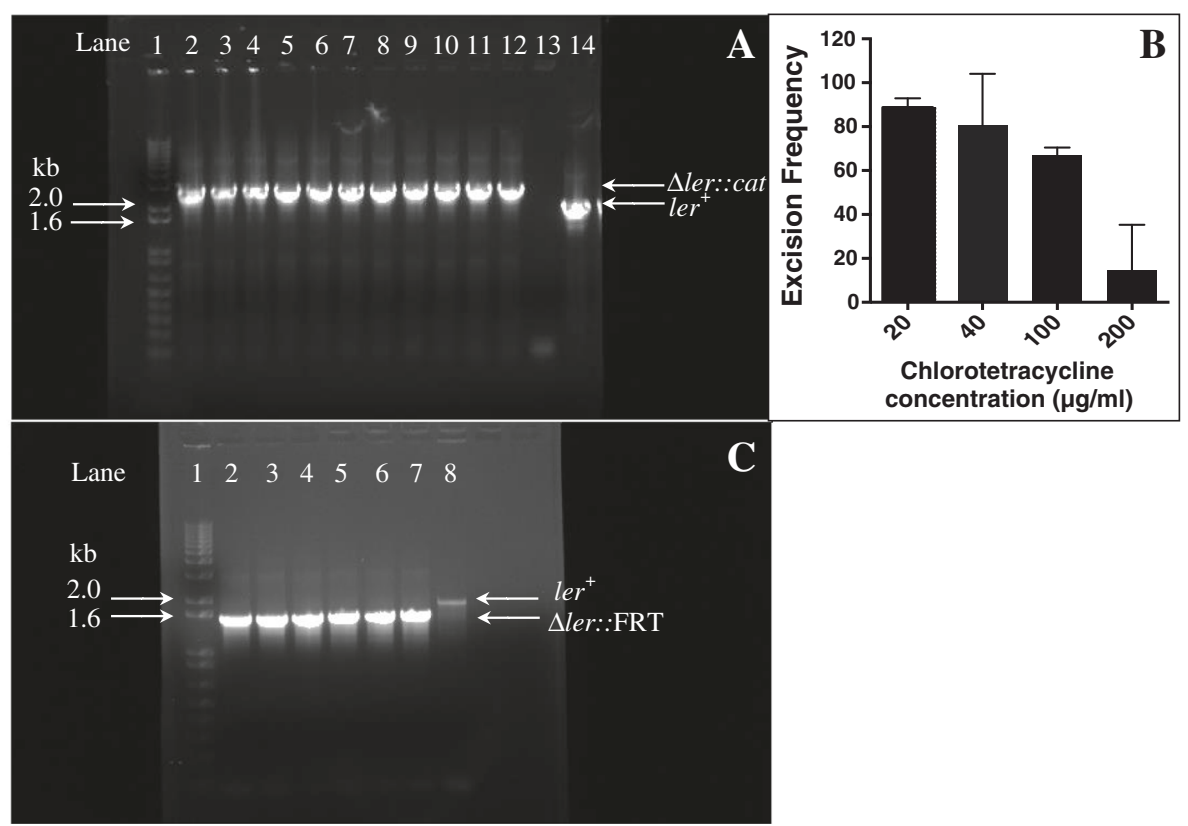

Fig. 1 a Locus specific PCR to confirm the replacement of ler ${ }^{+}$with $\Delta l e r:$ cat allele in E. albertii by recombineering. Twelve colonies that arose on chloramphenicol plates were screened by PCR, using a pair of primers, one of which bound upstream (SB2456) and the other downstream (SB2457) relative to the recombination site, to confirm that the $\mathrm{Cm}^{\mathrm{R}}$ phenotype resulted from the acquisition of the $\Delta$ ler:: $c$ at allele and the concomitant loss of the ler ${ }^{+}$allele. An aliquot (4 $\mu$ l) of each PCR product was electrophoresed on a $1 \%$ agarose gel and stained with ethidium bromide prior to visualization using a transilluminator (BioRad). All (lanes 2-12), but one (lane 13), isolates had successfully replaced the wild type ler ${ }^{+}$ allele ( 1.8 kb) with the mutant $\Delta$ ler::cat allele ( 2.5 kb). Lane 1 - 1 kb Tracklt ${ }^{\mathrm{TM}}$ Plus DNA Ladder; lanes $2-13$ - candidate $\Delta$ ler::cat recombinants; lane 14 - wild type ler $r^{+}$allele. $\mathbf{b}$ - Eviction of the cat cassette from the $\Delta l e r:$ cat locus. Recombinants were transformed with pFT-K, a thermolabile plasmid that expresses the FLP recombinase enzyme under the control of the TetR repressor. Varying concentration of chlorotetracycline $(20-200 \mu \mathrm{g} / \mathrm{ml}) \mathrm{was}$ added to derepress the flp gene and the frequency of excisants was calculated. The excision frequency was highest at the lowest chlorotetracycline concentration and gradually decreased with increasing chlorotetracycline concentration. Results depict the mean \pm standard deviation from a representative experiment involving two independently isolated recombinants. At least 36 candidate excisants per $\Delta$ ler::cat recombinant, or all if fewer arose, were phenotyped to determine the excision frequency. $\mathbf{c}$ - Locus specific PCR to confirm the eviction of the cat cassette from the Dler::cat recombinants. Excisants that were phenotypically $\mathrm{Cm}^{\text {S }}$ were screened by PCR using SB2456 \& SB2457 to confirm that resensitization to chloramphenicol occurred due to the loss of the cat cassette. All isolates that were phenotypically $\mathrm{Cm}^{\mathrm{S}}$ (lanes $2-7$ ) had evicted the cat cassette and gave a PCR product of the expected size ( 1.55 kb) compared to the wild type allele (lane $8 ; \sim 1.8 \mathrm{~kb})$. Lane $1-1$ kb Tracklt ${ }^{\mathrm{TM}}$ Plus DNA Ladder; lanes 2-7 - candidate $\Delta$ ler::FRT $\left(\mathrm{Cm}^{\mathrm{S}}\right)$ excisants; lane 8 - wild type ler $^{+}$allele

electroporated into hyperrecombinogenic bacteria using the optimized recombineering protocol. After recovering the cultures overnight, aliquots were spread onto LB plates supplemented with varying concentrations of kanamycin $(12.5-22.5 \mu \mathrm{g} / \mathrm{ml})$ and screened for $\mathrm{Kan}^{\mathrm{R}}$ recombinants. Two types of colonial morphologies were readily apparent on kanamycin plates: big sized colonies and punctiform satellite colonies. We observed that at a concentration of $12.5 \mu \mathrm{g} / \mathrm{ml}$ comparable numbers of big colonies were observed for both the transformed and untransformed control (data not shown). Some punctiform colonies were also observed $(<20 \mathrm{CFU})$. However, at higher kanamycin concentrations $(17.5-22.5 \mu \mathrm{g} / \mathrm{ml})$ big colonies were observed only in the case of the transformed cultures (17, 31 , and 34 recombinants/ $\mu \mathrm{g}$ of DNA on $17.5,20$, and $22.5 \mu \mathrm{g} / \mathrm{ml}$ of kanamycin respectively). Nonetheless, the number of punctiform satellite colonies remained unchanged (<20 CFU) at 17.5 and $20 \mu \mathrm{g} / \mathrm{ml}$ of kanamycin.
However, punctiform colonies were rarely observed at $22.5 \mu \mathrm{g} / \mathrm{ml}$ of kanamycin. Three big colonies were randomly picked from the LB plates containing the two highest concentrations of kanamycin ( 20 and $22.5 \mu \mathrm{g} / \mathrm{ml}$ ) and screened by PCR to confirm allelic replacement (Fig. 2a). Lanes 2-4 and 5-7 correspond to the PCR product obtained from potential recombinants that arose on plates containing 20 or $22.5 \mu \mathrm{g} / \mathrm{ml}$ of kanamycin respectively. All the candidate $\mathrm{Kan}^{\mathrm{R}}$ isolates had successfully replaced the $\operatorname{grl} R A$ operon with the $\triangle g r l R A:: k a n$ allele (Fig. 2a, lanes 27). Whereas $\Delta l e r:: c a t$ and $\Delta g r l R A:: k a n$ recombinants were readily obtained in $E$. albertii, recombination at the $h f q$ locus was relatively recalcitrant. No recombinants were observed in our first attempt whereas in the $2^{\text {nd }}$ attempt only $1 \mathrm{Cm}^{\mathrm{R}}$ isolate was observed after incubating the plates for $48 \mathrm{~h}$. This isolate was confirmed to have substituted $h f q^{+}$with the $\Delta h f q:: c a t$ allele (Fig. $2 \mathrm{~b}$, lanes $2-3)$. Previous reports suggest that the $h f q$ mutant in 


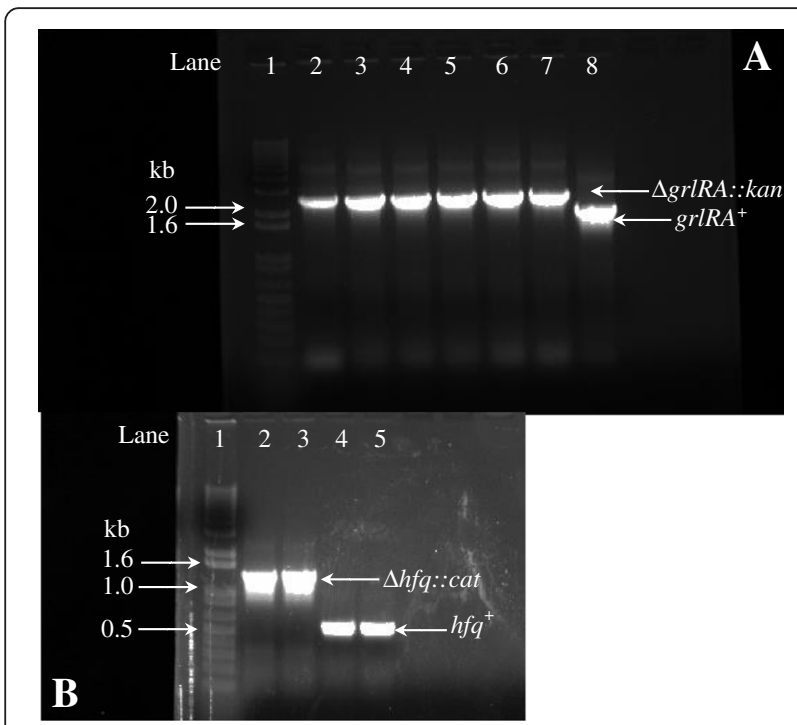

Fig. 2 Locus specific PCR to confirm the replacement of $g r l R A^{+}$with $\triangle g r l R A$ :.:kan allele (a) and $h f q^{+}$with $\triangle h f q:: c a t$ (b) in E. albertii by recombineering. $\mathbf{a}$ - Three colonies were selected from LB plates supplemented with kanamycin at 20 and at $22.5 \mu \mathrm{g} / \mathrm{ml}$ and screened by PCR using the primer pair SB2470 and SB2471 to confirm that the $\operatorname{Kan}^{\mathrm{R}}$ phenotype arose from the acquisition of the $\triangle$ grlRA:.kan cassette and the concomitant loss of the grlRA $A^{+}$locus. An aliquot (4 $\left.\mu \mathrm{l}\right)$ of each $\mathrm{PCR}$ reaction was electrophoresed and visualized essentially as described previously. All the $\operatorname{Kan}^{\mathrm{R}}$ isolates (lanes 2-7) tested positive for the mutant $\triangle$ grlRA.:kan allele $(\sim 2.3 \mathrm{~kb})$ and negative for the wild type allele ( 1.8 kb). Lane $1-1$ kb Tracklt ${ }^{\text {TM }}$ Plus DNA Ladder; Lanes 2-7 candidate $\triangle$ grlRA:.:kan recombinants isolated on $20 \mu \mathrm{g} / \mathrm{ml}$ (lanes 2-4) or $22.5 \mu \mathrm{g} / \mathrm{ml}$ kanamycin (lanes $5-7$ ). Lane 8 - wild type grlRA $A^{+}$allele. b - The only colony observed on the $\mathrm{Cm}$ plate $(6.25 \mu \mathrm{g} / \mathrm{ml})$ was verified by PCR, using the primer pair SB2485 and SB2486, to confirm the replacement of the $h \mathrm{fq}^{+}$allele ( $\left.527 \mathrm{bp}\right)$ with the $\Delta h f q:$ :cat allele ( 1.27 kb). Lane 1-1 kb Tracklt ${ }^{\mathrm{TM}}$ Plus DNA Ladder; Lanes 2-3 - replicate PCR reactions with the solitary $\mathrm{Cm}^{\mathrm{R}}$ isolate; Lanes 4-5 - replicate PCR reactions for the wild type $h f q^{+}$allele

E. coli, EHEC, and other phylogenetically related bacteria exhibits a pronounced growth defect and frequently accumulates suppressor mutations [101]. Moreover, the $h f q$ mutant is also hypersensitive to diverse stressors including genotoxic agents [101]. It is plausible that $h f q$ has an analogous role in $E$. albertii, which may explain the low mutational frequency at the $h f q$ locus in the bacterium.

\section{Conclusion}

The ability to reliably and rapidly mutagenize the genomes of bacterial pathogens by recombineering has enabled researchers to have a meticulous understanding of the environmental and regulatory controls of virulence genes, the mechanism of action of virulence factors, and the targets and traits controlled by these virulence factors. In particular, within the last decade the intricacies of pathogenicity accompanying $\mathrm{A} / \mathrm{E}$ pathogens, such as EPEC, EHEC, and Citrobacter rodentium have been unraveled and their arsenal of virulence determinants systematically characterized $[14,15,25,37]$. This has enabled researchers and health care providers to develop suitable treatments to counteract these pathogens. However, the virulence regulome of the related $\mathrm{A} / \mathrm{E}$ pathogen $E$. albertii remains cryptic, despite accumulating evidence that this bacterium causes disease in humans and birds and has been classified by the CDC as an emerging pathogen of significant public health concern [84, 102]. To date, not a single genome re-engineering technology has been reported for this bacterium. This is particularly disconcerting because a large-scale outbreak by $E$. albertii may have catastrophic consequences and lead to significant morbidity and mortality owing to our lack of understanding of its prevalence, molecular pathogenesis, and epidemiology.

In this report we have identified a set of conditions for successful lambda red mediated-recombineering of the genome of $E$. albertii. Briefly, hyperrecombinogenicity can be induced when the lambda red genes in pSIM6 are thermally induced at $42{ }^{\circ} \mathrm{C}$ for at least an hour prior to making cells electrocompetent. Electrocompetent cells are electroporated at $2.5 \mathrm{kV}$ with linear dsDNA substrate containing short terminal arms of $\sim 50$ nucleotide of homology to a target gene. Electroporated cells are recovered overnight at $37^{\circ} \mathrm{C} / 250 \mathrm{rpm}$ for $>16 \mathrm{~h}$ after which they are plated on selective media to identify candidate recombinants. Whereas these parameters are suitable for reproducible recombineering in E. albertii, however, the frequencies are $\sim 4$ orders of magnitude lower than what has been reported for nonpathogenic $E$. coli [28]. Moreover, consistent with previous observations in EPEC, EHEC, and E. coli $[23,25]$, recombination frequency is greatly affected by the plasmid expressing the lambda red proteins. Recombinants were readily and reproducibly obtained when the lambda red genes were expressed from pSIM6 but not from pKD46. The reason for this observation is unclear. Current efforts in our lab are dedicated towards identifying parameters for further optimizing recombineering in E. albertii. Several factors can influence homologous recombination. For instance, increasing the length of the homology arms as well as the amount of DNA can enhance recombination frequencies [26, 52, 103]. Similarly, oligonucleotide/ ssDNA-mediated recombineering yields more recombinants than dsDNA-mediated recombineering [28, 29]. Moreover, covalent modification of the $5^{\prime}$ end of ssDNA with a phosphorothioate linkage has been shown to further improve recombination in different bacterial hosts [39]. We are in the process of evaluating some of these parameters to potentiate lambda red mediated recombineering in E. albertii.

In conclusion, our formulated protocol for recombineering will enable researchers to construct a plethora of both marked and unmarked mutations in the genome of E. albertii. Genetic, biochemical, and phenotypic analysis 
of these mutants will not only shed light on the regulatory and signal transduction networks that govern virulence gene expression but also on the structure, function, mechanism of action, and regulon of the encodable virulence gene products.

\section{Methods}

\section{Bacterial Strains, Plasmids, Primers \& Media}

Bacteria were grown in Luria-Bertani (LB) broth supplemented with appropriate antibiotics when needed. The antibiotics used were chloramphenicol $(3.125-25 \mu \mathrm{g} / \mathrm{ml})$, kanamycin (12.5-25 $\mu \mathrm{g} / \mathrm{ml})$, chlorotetracycline (20$200 \mu \mathrm{g} / \mathrm{ml})$, and ampicillin $(100 \mu \mathrm{g} / \mathrm{ml})$. Strains and plasmids used in this study are listed in Table 1 whereas oligonucleotides are listed in Table 2. The E. coli strain DH5 $\alpha$ was used for the propagation and purification of plasmids.

Transformation of E. albertii with Plasmids Expressing the Lambda Red Enzymes

E. albertii strain Albert $19982^{\mathrm{T}}\left(\mathrm{LMG} 20976^{\mathrm{T}}=\right.$ CCUG $46494^{\mathrm{T}}$ ) was streaked onto LB plates and grown overnight at $37{ }^{\circ} \mathrm{C}$. The next day a single colony was inoculated into $5 \mathrm{ml}$ of $\mathrm{LB}$ and grown overnight at $37{ }^{\circ} \mathrm{C} /$ $250 \mathrm{rpm}$. The following day the overnight culture was subcultured 100 -fold into $30 \mathrm{ml}$ of LB and grown to an optical density of $\sim 0.6-0.8$. The culture was rendered electrocompetent by multiple washes with ice-cold $10 \%$ glycerol and concentrated to a final volume of $400 \mu \mathrm{l}$. Approximately $90 \mu \mathrm{l}$ of the culture was electroporated with $100 \mathrm{ng}$ of the plasmid pKD46 or pSIM6. The electroporants were recovered in $1 \mathrm{ml}$ of $\mathrm{LB}$ and grown for $3 \mathrm{~h}$ at $30{ }^{\circ} \mathrm{C}$, after which $200 \mu \mathrm{l}$ of the culture was spread onto LB plates supplemented with ampicillin $(100 \mu \mathrm{g} / \mathrm{ml})$ and grown overnight at $30{ }^{\circ} \mathrm{C}$. Two independently isolated colonies were picked and inoculated into $5 \mathrm{ml}$ of LB supplemented with ampicillin and grown overnight at $30{ }^{\circ} \mathrm{C} /$ $250 \mathrm{rpm}$. These cultures were archived at $-80{ }^{\circ} \mathrm{C}$ or used for recombineering. Our initial attempts at recombineering using pKD46 were either unsuccessful or yielded very few recombinants. However, allelic replacement was more efficient and reproducible when the lambda red enzymes were expressed from pSIM6. The protocol described herein describes chromosomal manipulations in E. albertii using pSIM6 and linear PCR products as substrates.

\section{PCR Conditions}

HiFi Taq DNA Polymerase was used for all PCR reactions essentially as described by the manufacturer (ThermoFisher Scientific). Typically, each PCR was performed in triplicate with each replicate containing $50 \mu \mathrm{l}$ of the reaction mix. The cat and kan cassettes were amplified from pKD3 and pKD13 respectively [23]. Briefly, a pair of chimeric primers was used to synthesize the desired dsPCR product to be used in recombineering. Each primer contains two distinct regions: a 3' region composed of $\sim 19-20$ nucleotides that hybridizes to the template (pKD3 or pKD13) and a nonhybridizable 5' region of $\sim 50$ nucleotides in length that is identical to the region immediately upstream or downstream of the

Table 1 Bacterial strains and plasmids used in this study

\begin{tabular}{|c|c|c|}
\hline Strain & Relevant genotype, phenotype & Reference/Source \\
\hline LS5494 & Escherichia albertii Albert $19982^{\top}$ & Manan Sharma \\
\hline LS5504 & LS5494(pSIM6), Amp ${ }^{R}$ (Ts) & This study \\
\hline LS5568 & LS5494_ler::cat, Cm ${ }^{R}$ Clone \#1 & This study \\
\hline LS5570 & LS5494_ler::cat, Cm Clone \#2 & This study \\
\hline LS5592 & LS5568(pFT-K), Cm ${ }^{R} \operatorname{Kan}^{R}$ (Ts) & This study \\
\hline LS5593 & LS5570(pFT-K), Cm ${ }^{R} \operatorname{Kan}^{R}$ (Ts) & This study \\
\hline LS5598 & LS5494_grlRA::kan, $\operatorname{Kan}^{R}$ & This study \\
\hline LS5607 & 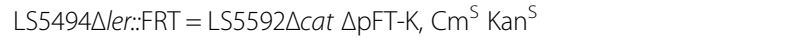 & This study \\
\hline LS5609 & 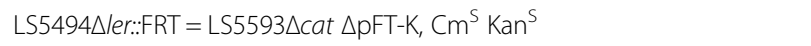 & This study \\
\hline LS5612 & 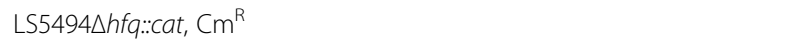 & This study \\
\hline $\mathrm{DH} 5 \mathrm{a}$ & 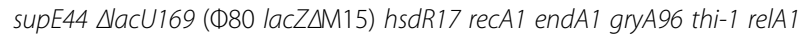 & Bettina Bommarius \\
\hline \multicolumn{3}{|c|}{ Plasmids } \\
\hline pSIM6 & $p_{L}$-gam-bet-exo genes under the control of Cl857 repressor, $\mathrm{Amp}^{\mathrm{R}}$ (Ts) & Don Court \\
\hline pKD46 & ParaBAD-gam-bet-exo under the control of $\mathrm{AraC}, \mathrm{Amp}^{\mathrm{R}}$ (Ts) & Barry Wanner \\
\hline pKD3 & Template plasmid to amplify FRT-cat-FRT amplicon, $\mathrm{Amp}^{\mathrm{R}} \mathrm{Cm}^{\mathrm{R}}$ & Barry Wanner \\
\hline pKD13 & Template plasmid to amplify FRT-kan-FRT amplicon, $\mathrm{Amp}^{R} \mathrm{Kan}^{R}$ & Barry Wanner \\
\hline pFT-K & flp gene under the control of $\operatorname{Tet}^{R}$ repressor, $\operatorname{Kan}^{R}$ (Ts) & Fred Blattner \\
\hline
\end{tabular}


Table 2 Oligonucleotides used in this study

\begin{tabular}{|c|c|c|}
\hline Primers & Purpose & Sequence \\
\hline SB2454 & 5' primer for replacing ler with cat & GATTAGGTCATTAATAGCTTAATATATTAAAGCATGCGGAGATTATTTATcatatgaatatcctcctta \\
\hline SB2455 & $3^{\prime}$ primer for replacing ler with cat & TATCGTTATCATCTAATGGTTITATATTAAATATTITTCAGCGGCATTAAgtgtaggctggagctgcttC \\
\hline SB2456 & $5^{\prime}$ primer to verify ler deletion & gcgGAATTCCCTTTAGCTCCTGGCACTTITGAAC \\
\hline SB2457 & 3' primer to verify ler deletion & gcgAAGCTTTGACGTAATATTTTATTCAGCTGAT \\
\hline SB2464 & 5' primer for replacing grlRA with kan & TGGATAGAACAAATTGAAAGGAGTGAGGTTGGTATGAAACTGAGTGAGTrgtgtaggctggagctgcttc \\
\hline SB2467 & 3' primer for replacing grlRA with kan & ATGTATGTGAAAAGTTATGTCTAACTCCCTIITITCCGTCTCATGATCATttccggggatccgtcgacct \\
\hline SB2470 & $5^{\prime}$ primer to verify grlRA deletion & gcgGAATTCTGAGCCTGTGGCACAATTGAT \\
\hline SB2471 & 3' primer to verify grlRA deletion & gcgAAGCTTGCAGTCTGATGAAGTGATCCC \\
\hline SB2481 & $5^{\prime}$ primer for replacing hfq with cat & TCAGAATCGAAAGGTTCAAAGTACAAATAAGCATATAAGGAAAAGAGAGAcatatgaatatcctcctta \\
\hline SB2482 & $3^{\prime}$ primer for replacing hfq with cat & AAAAACAGCCCGAAACCTTATTCGGTTCTTCGCTGTCCTGTTGCGCGGAgtgtaggctggagctgcttC \\
\hline SB2485 & 5' primer to verify hfa deletion & gcgGAATTCGCTATCGCAGGCTGAATGTGT \\
\hline SB2486 & 3' primer to verify hfa deletion & gcgAAGCTTACCAGCATCATAACGGTCAAA \\
\hline
\end{tabular}

Uppercase unbolded letters = oligonucleotide sequence homologous to the bacterial chromosome; lowercase letters = sequence complementary to the template pKD3 (for cat) or pKD13 (for kan); Uppercase bolded letters = Restriction sites; lowercase italicized letters - trinucleotide sequence flanking restriction sites

locus to be mutated. The PCR reaction yields an amplicon consisting of an FRT-cat/kan-FRT cassette that is flanked by two homology arms, each of which is 50 nucleotides in length. A double crossover event between the homology arms and their complementary sequences on the chromosome results in allelic replacement. The conditions for PCR were as follows: [Step 1: $94{ }^{\circ} \mathrm{C} / 5^{\prime}$; Step 2: $94{ }^{\circ} \mathrm{C} / 0.5^{\prime}$; Step 3: $43{ }^{\circ} \mathrm{C} / 0.5^{\prime}$; Step 4: $68^{\circ} \mathrm{C} / 2^{\prime}$; Step 5: Repeat steps 2-4 [x40 cycles]; Step 6: $72{ }^{\circ} \mathrm{C} / 7^{\prime}$; Step 7: $15{ }^{\circ} \mathrm{C}$ for $\infty$ ]. The synthesis of each amplicon was verified by gel electrophoresis and the PCR product was concentrated using the DNA Clean \& Concentrator $\mathrm{Kit}^{\mathrm{TM}}-25$ from Zymo Research (D4005) into a final volume of $25 \mu$ of elution buffer (10 mM Tris-HCl [pH 8.5], $0.1 \mathrm{mM}$ EDTA). The eluted PCR product was further concentrated by ethanol precipitation. Briefly, $2 \mu \mathrm{l}$ of glycogen $(20 \mathrm{mg} / \mathrm{ml}), 20 \mu \mathrm{l}$ of sodium acetate ( $\mathrm{pH} 5.2$ ), and $900 \mu \mathrm{l}$ of cold $100 \%$ ethanol $\left(-20{ }^{\circ} \mathrm{C}\right)$ were added to the eluted PCR product and thoroughly mixed. The sample was stored at $-20{ }^{\circ} \mathrm{C}$ for at least $30^{\prime}$ after which it was centrifuged at $4{ }^{\circ} \mathrm{C} / 16000 \mathrm{rpm}$ for $15^{\prime}$. The supernatant was discarded and the pellet washed with $500 \mu \mathrm{l}$ of $70 \%$ ethanol followed by centrifugation at $4{ }^{\circ} \mathrm{C} / 16000 \mathrm{rpm}$ for $5^{\prime}(3 \mathrm{x})$. After the last centrifugation step all the ethanol was vaporized and the sedimented pellet was resuspended in $10 \mu \mathrm{l}$ of molecular grade water.

\section{Preparation of Electrocompetent Cells for Recombineering}

E. albertii(pSIM6) transformants were streak purified onto pre-warmed $\mathrm{LB}+\mathrm{Amp}_{100}$ and incubated overnight at $30{ }^{\circ} \mathrm{C}$ to obtain axenic colonies. A single colony was inoculated into $5 \mathrm{ml}$ of $\mathrm{LB}+\mathrm{Amp}_{100}$ and incubated $\mathrm{ON}$ at $30{ }^{\circ} \mathrm{C} / 250 \mathrm{rpm}$. The overnight culture was diluted 100 fold in $30 \mathrm{ml}$ of $\mathrm{LB}+\mathrm{Amp}_{100}$ and grown at $30{ }^{\circ} \mathrm{C} /$ $250 \mathrm{rpm}$ in an incubator-shaker to an $\mathrm{OD}_{600}$ of $0.6-1.0$.
The cultures were then heat shocked at $42{ }^{\circ} \mathrm{C} / 250 \mathrm{rpm}$ for $1 \mathrm{~h}$ in a water bath to induce the expression of the lambda red exo, bet, and gam genes from pSIM6. The pSIM family of plasmids was engineered in the lab of Don Court at the National Institutes of Health $(\mathrm{NIH})$ [28]. Note that we, and other researchers, have observed that recombineering is more efficient when the cultures are thermally induced in a water-shaker as opposed to an air-shaker (data not shown). After induction the cultures were rapidly chilled by swirling in an ice-water bath for $\sim 2$ ' and then transferred to pre-chilled $50 \mathrm{ml}$ conical tubes. The cultures were then centrifuged at $4100 \mathrm{rpm} / 4^{\circ} \mathrm{C} / 10^{\prime}$. Subsequently, the supernatant was discarded and each pellet was initially resuspended in $1 \mathrm{ml}$ of ice-cold $10 \%$ glycerol after which the volume was increased to $30 \mathrm{ml}$ by the addition of $29 \mathrm{ml}$ of icecold $10 \%$ glycerol. The centrifugation step was repeated and the supernatant discarded. This was followed by suspending the pellet in $1 \mathrm{ml}$ of ice-cold $10 \%$ glycerol and transferring the suspension to a pre-chilled microcentrifuge tube. The tubes were centrifuged at $10,000 \mathrm{rpm} / 4^{\circ} \mathrm{C} / 2^{\prime}$ and the supernatant discarded. The washes with ice-cold $10 \%$ glycerol were repeated a minimum of 3 times. After the last wash the pellet was resuspended in $400 \mu \mathrm{l}$ of ice-cold $10 \%$ glycerol. Approximately $90 \mu \mathrm{l}$ of electrocompetent cells were aliquoted into microcentrifuge tubes and $1.5 \mu \mathrm{g}$ of the ethanol precipitated PCR product was added to the chilled culture. For the negative control no PCR product was added. The mixture was incubated on ice for $\sim 1$ ' after which it was transferred to a pre-chilled cuvette and electroporation was performed at a voltage of $\sim 1.8-$ $2.5 \mathrm{kV}$. Immediately after electroporation the cells were recovered in $1 \mathrm{ml}$ of $\mathrm{LB}$ and then transferred to a test tube containing $9 \mathrm{ml}$ of $\mathrm{LB}$. The recoverants were 
incubated at $37{ }^{\circ} \mathrm{C} / 250 \mathrm{rpm}$ for at least $16 \mathrm{~h}$. The next day $1.5 \mathrm{ml}$ of the overnight grown culture was transferred to microcentrifuge tubes and pelleted by centrifugation at $16000 \mathrm{rpm} / 2^{\prime}$. The supernatant was discarded and the pellet resuspended in $\sim 150-200 \mu \mathrm{l}$ of LB broth, after which, the cell suspension was plated on LB plates supplemented with chloramphenicol $(3.125-25 \mu \mathrm{g} / \mathrm{ml})$ or kanamycin $(15-22.5 \mu \mathrm{g} / \mathrm{ml})$. The plates were incubated at $37{ }^{\circ} \mathrm{C}$ for $\sim 1-2$ days until recombinants were observed. Once recombinants arose then individual colonies were inoculated into $50 \mu \mathrm{l}$ of LB and incubated for $\sim 3 \mathrm{~h}$ at $37{ }^{\circ} \mathrm{C}$. Locus-specific PCR was performed on $2 \mu \mathrm{l}$ of the culture to verify the replacement of the chromosomal allele with the mutant allele.

\section{Curing of pSIM6}

Once recombinants had been identified then $\sim 2 \mu \mathrm{l}$ of the culture was streaked onto $\mathrm{LB}+\mathrm{Cm}_{6.25} / \mathrm{Kan}_{22.5}$ plates and incubated overnight at $42{ }^{\circ} \mathrm{C}$. The next day a few colonies were picked from each sector and patch plated onto $\mathrm{LB}+\mathrm{Cm} / \mathrm{Kan}$ and $\mathrm{LB}+\mathrm{Amp}$ plates and incubated overnight at $30{ }^{\circ} \mathrm{C}$. The vast majority of the $\mathrm{Cm}^{\mathrm{R}}$ or $\mathrm{Kan}^{\mathrm{R}}$ recombinants were phenotypically $\mathrm{Amp}^{\mathrm{S}}$ suggesting that the resident plasmid pSIM6 had been cured from the recombinants.

\section{Eviction of the Drug Resistance Cassette}

To evict the cat cassette, the recombinants were transformed with the plasmid pFT-K [104]. Transformation was done essentially as described above. $\mathrm{pFT}-\mathrm{K}$ is a thermolabile replicon that confers temperature-sensitive resistance to kanamycin $(25 \mu \mathrm{g} / \mathrm{ml})$ and expresses the $f l p$ recombinase under the control of the tetracycline repressor (TetR) of the transposon Tn10. All the $\mathrm{Kan}^{\mathrm{R}}$ transformants that were observed were pooled together into $20 \mathrm{ml}$ of LB supplemented with kanamycin and grown overnight at $30{ }^{\circ} \mathrm{C} / 250 \mathrm{rpm}$. The overnight grown culture was diluted 100 fold into fresh identical media and incubated at $30{ }^{\circ} \mathrm{C}$ under static conditions for $24 \mathrm{~h}$. The following day the FLP recombinase was induced by diluting the overnight culture 4 fold in $20 \mathrm{ml}$ of LB supplemented with unautoclaved chlorotetracycline, at a range of concentrations $(20-200 \mu \mathrm{g} / \mathrm{ml})$, and growing overnight at $30{ }^{\circ} \mathrm{C}$ under static conditions. Chlorotetracycline binds to and inactivates the TetR repressor thereby derepressing the $f l p$ gene. FLP recombinase, in turn, recognizes and catalyzes the site-specific recombination between the two direct repetitive FRT sites to evict the bracketed cat resistance cassette, leaving behind a solitary residual FRT site. As a consequence, the engineered bacterial excisant becomes resensitized to chloramphenicol. After overnight induction of the cultures, a loopful of bacteria was streaked onto nonselective LB plates and incubated overnight at $42{ }^{\circ} \mathrm{C}$ to cure the thermolabile plasmid. The next day $\sim 36$ independently isolated colonies were spot-streaked onto $\mathrm{LB}, \mathrm{LB}+\mathrm{Cm}$, and $\mathrm{LB}+\mathrm{Kan}$ and incubated overnight at $30{ }^{\circ} \mathrm{C}$ to screen for the $\mathrm{Cm}^{\mathrm{S}}$ excisants that had also been cured of the plasmid $\left(\mathrm{Kan}^{\mathrm{S}}\right)$. If the excisant had not been cured of the plasmid then the $\mathrm{Cm}^{\mathrm{S}}$ isolate was re-streaked onto fresh $\mathrm{LB}$ plates and incubated for another night at $42{ }^{\circ} \mathrm{C}$ to cure the plasmid. The genotype of the excisants was further verified by PCR as described above.

\begin{abstract}
Abbreviations
EPEC: enteropathogenic Escherichia coli; EHEC: enterohemorrhagic Escherichia coli; EAEC: enteroaggregative Escherichia coli; LEE: locus of enterocyte effacement; Ler: LEE encoded regulator; GrlR: global regulator of the LEE repressor; GrIA: global regulator of the LEE activator; Hfa: host factor essential for the replication of the bacteriophage QB; PCR: polymerase chain reaction; dsDNA: double stranded DNA; ssDNA: single stranded DNA; eae: E. coli attaching and effacing; rRNA: ribosomal RNA; stx: Shiga toxin; ICDDR-B: International Centre for Diarrheal Disease Research, Bangladesh.
\end{abstract}

\section{Competing interests}

The authors declare that they have no competing interests.

\section{Authors' contributions}

ME and SB conceived the research. ME, JR, CX, CU, and SB performed the research. ME and SB analyzed the data and wrote the manuscript. CU and SB contributed reagents. All authors read and approved the final manuscript.

\section{Acknowledgements}

This research was supported by start-up funds provided by Saint Joseph's University (SJU) with additional financial and infrastructural support generously provided by the Biology department at SJU. We thank Manan Sharma for his generous gift of the different E. albertii isolates and Donald Court for the different pSIM plasmids and suggestions on recombineering. S.B. is eternally grateful and indebted to Gigi Storz (NIH/NICHD) and Chris Weingart (Denison University) for their support and mentoring throughout his academic, research, and pedagogical endeavors. M.E. is a John P. McNulty Scholar and recipient of the Thermo Scientific Pierce Scholarship award.

\section{Author details}

${ }^{1}$ Department of Biology, Saint Joseph's University, 5600 City Avenue, Philadelphia, PA 19131, USA. ²Department of Mathematics, Saint Joseph's University, 5600 City Avenue, Philadelphia, PA 19131, USA. ${ }^{3}$ Howard Hughes Medical Institute, Columbia University Medical Center, Columbia, USA. ${ }^{4}$ Columbia University Medical Center, 1051 Riverside Drive, New York, NY 10032, USA. ${ }^{5}$ Present address: Microbiology Department, Perelman School of Medicine, University of Pennsylvania, 3610 Hamilton Walk, 221 Johnson Pavilion, Philadelphia, PA 19104, USA. ${ }^{6}$ Present address: Bluemle Life Sciences Building, Thomas Jefferson University, 233 South Tenth Street, Philadelphia, PA 19107, USA.

Received: 18 October 2015 Accepted: 29 December 2015

Published online: 03 February 2016

\section{References}

1. Shuman HA, Silhavy TJ. The art and design of genetic screens: Escherichia coli. Nat Rev Genet. 2003:4(6):419-31.

2. Schweizer $H$. Bacterial genetics: past achievements, present state of the field, and future challenges. Biotechniques. 2008;44(5):633-4. 6-41.

3. Weinstock GM. Genomics and bacterial pathogenesis. Emerg Infect Dis. 2000;6(5):496-504.

4. Parkhill J, Wren BW. Bacterial epidemiology and biology-lessons from genome sequencing. Genome Biol. 2011;12(10):230.

5. Kim Y, Oh S, Park S, Kim SH. Interactive transcriptome analysis of enterohemorrhagic Escherichia coli (EHEC) O157:H7 and intestinal epithelial HT-29 cells after bacterial attachment. Int J Food Microbiol. 2009;131(2-3):224-32.

6. Landstorfer R, Simon S, Schober S, Keim D, Scherer S, Neuhaus K. Comparison of strand-specific transcriptomes of enterohemorrhagic Escherichia coli 0157:H7 EDL933 (EHEC) under eleven different 
environmental conditions including radish sprouts and cattle feces. BMC Genomics. 2014;15:353.

7. Gruber CC, Sperandio V. Global analysis of posttranscriptional regulation by GImY and GImZ in enterohemorrhagic Escherichia coli O157:H7. Infect Immun. 2015;83(4):1286-95.

8. Hazen TH, Daugherty SC, Shetty A, Mahurkar AA, White O, Kaper JB, et al. RNA-Seq analysis of isolate- and growth phase-specific differences in the global transcriptomes of enteropathogenic Escherichia coli prototype isolates. Front Microbiol. 2015;6:569.

9. Law HT, Chua M, Moon KM, Foster LJ, Guttman JA. Mass SpectrometryBased Proteomics Identification of Enteropathogenic Escherichia coli Pedestal Constituents. J Proteome Res. 2015;14(6):2520-7.

10. Hardwidge PR, Donohoe S, Aebersold R, Finlay BB. Proteomic analysis of the binding partners to enteropathogenic Escherichia coli virulence proteins expressed in Saccharomyces cerevisiae. Proteomics. 2006;6(7):2174-9.

11. Hansen AM, Chaerkady R, Sharma J, Diaz-Mejia JJ, Tyagi N, Renuse S, et al. The Escherichia coli phosphotyrosine proteome relates to core pathways and virulence. PLoS Pathog. 2013;9(6):e1003403.

12. Bommarius B, Anyanful A, Izrayelit $Y$, Bhatt S, Cartwright E, Wang W, et al. A family of indoles regulate virulence and Shiga toxin production in pathogenic E. coli. PLoS One. 2013;8(1):e54456.

13. Cevallos-Cevallos JM, Danyluk MD, Reyes-De-Corcuera Jl. GC-MS based metabolomics for rapid simultaneous detection of Escherichia coli O157:H7, Salmonella Typhimurium, Salmonella Muenchen, and Salmonella Hartford in ground beef and chicken. J Food Sci. 2011;76(4):M238-46.

14. Mellies JL, Barron AM, Carmona AM. Enteropathogenic and enterohemorrhagic Escherichia coli virulence gene regulation. Infect Immun. 2007;75(9):4199-210.

15. Bhatt $\mathrm{S}$, Romeo T, Kalman D. Honing the message: post-transcriptional and post-translational control in attaching and effacing pathogens. Trends Microbiol. 2011;19(5):217-24.

16. Jobichen C, Li M, Yerushalmi G, Tan YW, Mok YK, Rosenshine I, et al. Structure of GrlR and the implication of its EDED motif in mediating the regulation of type III secretion system in EHEC. PLoS Pathog. 2007;3(5):e69.

17. Padavannil A, Jobichen C, Mills E, Velazquez-Campoy A, Li M, Leung KY, et al. Structure of GrlR-GrlA complex that prevents GrlA activation of virulence genes. Nat Commun. 2013;4:2546.

18. Kendall MM, Gruber CC, Rasko DA, Hughes DT, Sperandio V. Hfa virulence regulation in enterohemorrhagic Escherichia coli O157:H7 strain 86-24. J Bacteriol. 2011;193(24):6843-51.

19. Shakhnovich EA, Davis BM, Waldor MK. Hfq negatively regulates type III secretion in EHEC and several other pathogens. Mol Microbiol. 2009;74(2):347-63.

20. Bingle LE, Constantinidou C, Shaw RK, Islam MS, Patel M, Snyder LA, et al. Microarray analysis of the Ler regulon in enteropathogenic and enterohaemorrhagic Escherichia coli strains. PLoS One. 2014;9(1):e80160.

21. Quandt J, Hynes MF. Versatile suicide vectors which allow direct selection for gene replacement in gram-negative bacteria. Gene. 1993;127(1):15-21.

22. Kaniga K, Delor I, Cornelis GR. A wide-host-range suicide vector for improving reverse genetics in gram-negative bacteria: inactivation of the blaA gene of Yersinia enterocolitica. Gene. 1991;109(1):137-41.

23. Datsenko KA, Wanner BL. One-step inactivation of chromosomal genes in Escherichia coli K-12 using PCR products. Proc Natl Acad Sci U S A. 2000;97(12):6640-5.

24. Uzzau S, Figueroa-Bossi N, Rubino S, Bossi L. Epitope tagging of chromosomal genes in Salmonella. Proc Natl Acad Sci U S A. 2001;98(26):15264-9.

25. Murphy KC, Campellone KG. Lambda Red-mediated recombinogenic engineering of enterohemorrhagic and enteropathogenic E. coli. BMC Mol Biol. 2003;4:11

26. Murphy KC, Campellone KG, Poteete AR. PCR-mediated gene replacement in Escherichia coli. Gene. 2000;246(1-2):321-30.

27. Court DL, Swaminathan $S, Y u$ D, Wilson $H$, Baker T, Bubunenko $M$, et al. Mini-lambda: a tractable system for chromosome and BAC engineering. Gene. 2003;315:63-9.

28. Datta S, Costantino N, Court DL. A set of recombineering plasmids for gram-negative bacteria. Gene. 2006;379:109-15.

29. Datta S, Costantino N, Zhou X, Court DL. Identification and analysis of recombineering functions from Gram-negative and Gram-positive bacteria and their phages. Proc Natl Acad Sci U S A. 2008;105(5):1626-31.

30. Warming S, Costantino N, Court DL, Jenkins NA, Copeland NG. Simple and highly efficient BAC recombineering using galK selection. Nucleic Acids Res. 2005;33(4):e36.
31. Sharan SK, Thomason LC, Kuznetsov SG, Court DL. Recombineering: a homologous recombination-based method of genetic engineering. Nat Protoc. 2009;4(2):206-23.

32. Zhang Y, Buchholz F, Muyrers JP, Stewart AF. A new logic for DNA engineering using recombination in Escherichia coli. Nat Genet. 1998:20(2):123-8.

33. Reyrat JM, Pelicic V, Gicquel B, Rappuoli R. Counterselectable markers: untapped tools for bacterial genetics and pathogenesis. Infect Immun. 1998;66(9):4011-7.

34. Kalogeraki VS, Winans SC. Suicide plasmids containing promoterless reporter genes can simultaneously disrupt and create fusions to target genes of diverse bacteria. Gene. 1997;188(1):69-75.

35. Bhatt S, Edwards AN, Nguyen HT, Merlin D, Romeo T, Kalman D. The RNA binding protein CsrA is a pleiotropic regulator of the locus of enterocyte effacement pathogenicity island of enteropathogenic Escherichia coli. Infect Immun. 2009;77(9):3552-68.

36. Deng W, Li Y, Hardwidge PR, Frey EA, Pfuetzner RA, Lee S, et al. Regulation of type III secretion hierarchy of translocators and effectors in attaching and effacing bacterial pathogens. Infect Immun. 2005;73(4):2135-46.

37. Deng W, Puente JL, Gruenheid S, Li Y, Vallance BA, Vazquez A, et al. Dissecting virulence: systematic and functional analyses of a pathogenicity island. Proc Natl Acad Sci U S A. 2004;101(10):3597-602.

38. Donnenberg MS, Kaper JB. Construction of an eae deletion mutant of enteropathogenic Escherichia coli by using a positive-selection suicide vector. Infect Immun. 1991;59(12):4310-7.

39. Mosberg JA, Lajoie MJ, Church GM. Lambda red recombineering in Escherichia coli occurs through a fully single-stranded intermediate. Genetics. 2010;186(3):791-9.

40. Yu D, Sawitzke JA, Ellis H, Court DL. Recombineering with overlapping single-stranded DNA oligonucleotides: testing a recombination intermediate. Proc Natl Acad Sci U S A. 2003;100(12):7207-12.

41. Murphy KC. Use of bacteriophage lambda recombination functions to promote gene replacement in Escherichia coli. J Bacteriol. 1998;180:2063-71.

42. Joseph JW, Kolodner R. Exonuclease VIII of Escherichia coli. II. Mechanism of action. J Biol Chem. 1983;258(17):10418-24.

43. Clark AJ, Sandler SJ, Willis DK, Chu CC, Blanar MA, Lovett ST. Genes of the RecE and RecF pathways of conjugational recombination in Escherichia coli. Cold Spring Harb Symp Quant Biol. 1984:49:453-62.

44. Hall SD, Kane MF, Kolodner RD. Identification and characterization of the Escherichia coli RecT protein, a protein encoded by the recE region that promotes renaturation of homologous single-stranded DNA. J Bacteriol. 1993;175(1):277-87.

45. Sawitzke JA, Costantino N, Li XT, Thomason LC, Bubunenko M, Court C, et al. Probing cellular processes with oligo-mediated recombination and using the knowledge gained to optimize recombineering. J Mol Biol. 2011;407(1):45-59.

46. Little JW. An exonuclease induced by bacteriophage lambda. II. Nature of the enzymatic reaction. J Biol Chem. 1967;242(4):679-86.

47. Li Z, Karakousis G, Chiu SK, Reddy G, Radding CM. The beta protein of phage lambda promotes strand exchange. J Mol Biol. 1998;276(4):733-44.

48. Karakousis G, Ye N, Li Z, Chiu SK, Reddy G, Radding CM. The beta protein of phage lambda binds preferentially to an intermediate in DNA renaturation. J Mol Biol. 1998:276(4):721-31.

49. Unger RC, Clark AJ. Interaction of the recombination pathways of bacteriophage lambda and its host Escherichia coli K12: effects on exonuclease V activity. J Mol Biol. 1972;70(3):539-48.

50. Kulkarni SK, Stahl FW. Interaction between the sbcC gene of Escherichia coli and the gam gene of phage lambda. Genetics. 1989;123(2):249-53.

51. Court DL, Sawitzke JA, Thomason LC. Genetic engineering using homologous recombination. Annu Rev Genet. 2002;36:361-88.

52. Ellis HM, Yu D, DiTizio T, Court DL. High efficiency mutagenesis, repair, and engineering of chromosomal DNA using single-stranded oligonucleotides. Proc Natl Acad Sci U S A. 2001;98(12):6742-6.

53. Zhang Y, Muyrers JP, Rientjes J, Stewart AF. Phage annealing proteins promote oligonucleotide-directed mutagenesis in Escherichia coli and mouse ES cells. BMC Mol Biol. 2003;4(1):1.

54. Savage PJ, Leong JM, Murphy KC. Rapid allelic exchange in enterohemorrhagic Escherichia coli (EHEC) and other E. coli using lambda red recombination. Curr Protoc Microbiol. 2006; Chapter 5:Unit5A 2.

55. Croxen MA, Finlay BB. Molecular mechanisms of Escherichia coli pathogenicity. Nat Rev Microbiol. 2010;8(1):26-38. 
56. Campellone KG, Leong JM. Tails of two Tirs: actin pedestal formation by enteropathogenic E. coli and enterohemorrhagic E. coli O157:H7. Curr Opin Microbiol. 2003;6(1):82-90.

57. Bhavsar AP, Guttman JA, Finlay BB. Manipulation of host-cell pathways by bacterial pathogens. Nature. 2007;449(7164):827-34.

58. McDaniel TK, Kaper JB. A cloned pathogenicity island from enteropathogenic Escherichia coli confers the attaching and effacing phenotype on E. coli K-12. Mol Microbiol. 1997;23(2):399-407.

59. Donnenberg MS, Tacket CO, James SP, Losonsky G, Nataro JP, Wasserman SS, et al. Role of the eaeA gene in experimental enteropathogenic Escherichia coli infection. J Clin Invest. 1993;92(3):1412-7.

60. Dziva F, van Diemen PM, Stevens MP, Smith AJ, Wallis TS. Identification of Escherichia coli 0157: H7 genes influencing colonization of the bovine gastrointestinal tract using signature-tagged mutagenesis. Microbiology. 2004;150(Pt 11):3631-45

61. Ritchie JM, Waldor MK. The locus of enterocyte effacement-encoded effector proteins all promote enterohemorrhagic Escherichia coli pathogenicity in infant rabbits. Infect Immun. 2005;73(3):1466-74.

62. Ogino T, Ohno R, Sekiya K, Kuwae A, Matsuzawa T, Nonaka T, et al. Assembly of the type III secretion apparatus of enteropathogenic Escherichia coli. J Bacteriol. 2006;188(8):2801-11.

63. Sekiya K, Ohishi M, Ogino T, Tamano K, Sasakawa C, Abe A. Supermolecular structure of the enteropathogenic Escherichia coli type III secretion system and its direct interaction with the EspA-sheath-like structure. Proc Natl Acad Sci U S A. 2001;98(20):11638-43.

64. Shaw RK, Daniell S, Ebel F, Frankel G, Knutton S. EspA filament-mediated protein translocation into red blood cells. Cell Microbiol. 2001;3(4):213-22.

65. Knutton S, Rosenshine I, Pallen MJ, Nisan I, Neves BC, Bain C, et al. A novel EspA-associated surface organelle of enteropathogenic Escherichia coli involved in protein translocation into epithelial cells. Embo J. 1998;17(8):2166-76.

66. Taylor KA, O'Connell CB, Luther PW, Donnenberg MS. The EspB protein of enteropathogenic Escherichia coli is targeted to the cytoplasm of infected HeLa cells. Infect Immun. 1998;66(11):5501-7.

67. Wachter C, Beinke C, Mattes M, Schmidt MA. Insertion of EspD into epithelial target cell membranes by infecting enteropathogenic Escherichia coli. Mol Microbiol. 1999:31(6):1695-707.

68. Wang D, Roe AJ, McAteer S, Shipston MJ, Gally DL. Hierarchal type III secretion of translocators and effectors from Escherichia coli 0157:H7 requires the carboxy terminus of SepL that binds to Tir. Mol Microbiol. 2008;69(6):1499-512.

69. Wilson RK, Shaw RK, Daniell S, Knutton S, Frankel G. Role of EscF, a putative needle complex protein, in the type III protein translocation system of enteropathogenic Escherichia coli. Cell Microbiol. 2001;3(11):753-62.

70. Jimenez R, Cruz-Migoni SB, Huerta-Saquero A, Bustamante VH, Puente JL. Molecular characterization of GrlA, a specific positive regulator of ler expression in enteropathogenic Escherichia coli. J Bacteriol. 2010;192(18):4627-42.

71. Berdichevsky T, Friedberg D, Nadler C, Rokney A, Oppenheim A, Rosenshine I. Ler is a negative autoregulator of the LEE1 operon in enteropathogenic Escherichia coli. J Bacteriol. 2005;187(1):349-57.

72. Umanski T, Rosenshine I, Friedberg D. Thermoregulated expression of virulence genes in enteropathogenic Escherichia coli. Microbiology. 2002;148(Pt 9):2735-44.

73. Franzin FM, Sircili MP. Locus of enterocyte effacement: a pathogenicity island involved in the virulence of enteropathogenic and enterohemorragic Escherichia coli subjected to a complex network of gene regulation. Biomed Res Int. 2015;2015:534738.

74. Islam MS, Shaw RK, Frankel G, Pallen MJ, Busby SJ. Translation of a minigene in the $5^{\prime}$ leader sequence of the enterohaemorrhagic Escherichia coli LEE1 transcription unit affects expression of the neighbouring downstream gene. Biochem J. 2012:441(1):247-53.

75. Elliott SJ, Sperandio V, Giron JA, Shin S, Mellies J, Wainwright L, et al. The Locus of Enterocyte Effacement (LEE)-Encoded Regulator Controls Expression of Both LEE- and Non-LEE-Encoded Virulence Factors in Enteropathogenic and Enterohemorrhagic Escherichia coli. Infect Immun. 2000;68(11):6115-26.

76. Mellies JL, Elliott SJ, Sperandio V, Donnenberg MS, Kaper JB. The Per regulon of enteropathogenic Escherichia coli : identification of a regulatory cascade and a novel transcriptional activator, the locus of enterocyte effacement (LEE)-encoded regulator (Ler). Mol Microbiol. 1999;33(2):296-306.

77. Bhatt S, Anyanful A, Kalman D. CsrA and TnaB Coregulate Tryptophanase Activity To Promote Exotoxin-Induced Killing of Caenorhabditis elegansby Enteropathogenic Escherichia coli. J Bacteriol. 2011;193(17):4516-22.
78. Gruber CC, Sperandio V. Global analysis of post-transcriptional regulation by GImY and GImZ in enterohemorrhagic E. coli (EHEC) 0157:H7. Infect Immun. 2015;82(4):1286-95.

79. Albert MJ, Alam K, Islam M, Montanaro J, Rahaman AS, Haider K, et al. Hafnia alvei, a probable cause of diarrhea in humans. Infect Immun. 1991;59(4):1507-13.

80. Albert MJ, Faruque SM, Ansaruzzaman M, Islam MM, Haider K, Alam K, et al. Sharing of virulence-associated properties at the phenotypic and genetic levels between enteropathogenic Escherichia coli and Hafnia alvei. J Med Microbiol. 1992;37(5):310-4.

81. Ridell J, Siitonen A, Paulin L, Lindroos O, Korkeala H, Albert MJ. Characterization of Hafnia alvei by biochemical tests, random amplified polymorphic DNA PCR, and partial sequencing of 165 rRNA gene. J Clin Microbiol. 1995;33(9):2372-6.

82. Abbott SL, O'Connor J, Robin T, Zimmer BL, Janda JM. Biochemical properties of a newly described Escherichia species, Escherichia albertii. J Clin Microbiol. 2003;41(10):4852-4.

83. Huys G, Cnockaert M, Janda JM, Swings J. Escherichia albertii sp. nov., a diarrhoeagenic species isolated from stool specimens of Bangladeshi children. Int J Syst Evol Microbiol. 2003;53(Pt 3):807-10.

84. Ooka T, Seto K, Kawano K, Kobayashi H, Etoh Y, Ichihara S, et al. Clinical significance of Escherichia albertii. Emerg Infect Dis. 2012;18(3):488-92.

85. Asoshima N, Matsuda M, Shigemura K, Honda M, Yoshida H, Hiwaki H, et al. Identification of Escherichia albertii as a causative agent of a food-borne outbreak occurred in 2003. Jpn J Infect Dis. 2014;67:139-40.

86. Ooka T, Tokuoka E, Furukawa M, Nagamura T, Ogura Y, Arisawa K, et al. Human gastroenteritis outbreak associated with Escherichia albertii, Japan. Emerg Infect Dis. 2013;19(1):144-6.

87. Brandal LT, Tunsjo HS, Ranheim TE, Lobersli I, Lange H, Wester AL. Shiga toxin 2a in Escherichia albertii. J Clin Microbiol. 2015:53(4):1454-5.

88. Persson S, Olsen KE, Ethelberg S, Scheutz F. Subtyping method for Escherichia coli shiga toxin (verocytotoxin) 2 variants and correlations to clinical manifestations. J Clin Microbiol. 2007;45(6):2020-4.

89. Fuller CA, Pellino CA, Flagler MJ, Strasser JE, Weiss AA. Shiga toxin subtypes display dramatic differences in potency. Infect Immun. 2011;79(3):1329-37.

90. Russo LM, Melton-Celsa AR, Smith MA, Smith MJ, O'Brien AD. Oral intoxication of mice with Shiga toxin type $2 \mathrm{a}$ (Stx2a) and protection by anti-Stx2a monoclonal antibody 11E10. Infect Immun. 2014;82(3):1213-21.

91. Eklund M, Leino K, Siitonen A. Clinical Escherichia coli strains carrying stx genes: stx variants and stx-positive virulence profiles. J Clin Microbiol. 2002:40(12):4585-93.

92. Bielaszewska M, Mellmann A, Bletz S, Zhang W, Kock R, Kossow A, et al. Enterohemorrhagic Escherichia coli O26:H11/H-: a new virulent clone emerges in Europe. Clin Infect Dis. 2013;56(10):1373-81.

93. Beutin L, Hammerl JA, Reetz J, Strauch E. Shiga toxin-producing Escherichia coli strains from cattle as a source of the Stx2a bacteriophages present in enteroaggregative Escherichia coli 0104:H4 strains. Int J Med Microbiol. 2013;303(8):595-602.

94. Hansen AM, Kaper JB. Hfq affects the expression of the LEE pathogenicity island in enterohaemorrhagic Escherichia coli. Mol Microbiol. 2009;73(3): 446-65.

95. Fiedoruk K, Daniluk T, Swiecicka I, Murawska E, Sciepuk M, Leszczynska K. First Complete Genome Sequence of Escherichia albertii Strain KF1, a New Potential Human Enteric Pathogen. Genome Announc. 2014;2(1). doi:10.1128/genomeA.00004-14.

96. Pallen MJ, Beatson SA, Bailey CM. Bioinformatics analysis of the locus for enterocyte effacement provides novel insights into type-III secretion. BMC Microbiol. 2005:5:9.

97. Gartner JF, Schmidt MA. Comparative analysis of locus of enterocyte effacement pathogenicity islands of atypical enteropathogenic Escherichia coli. Infect Immun. 2004:72(11):6722-8.

98. Bustamante VH, Villalba MI, Garcia-Angulo VA, Vazquez A, Martinez LC, Jimenez $\mathrm{R}$, et al. PerC and GrlA independently regulate Ler expression in enteropathogenic Escherichia coli. Mol Microbiol. 2011;82(2):398-415.

99. Waters LS, Storz G. Regulatory RNAs in bacteria. Cell. 2009;136(4):615-28.

100. Van Assche E, Van Puyvelde S, Vanderleyden J, Steenackers HP. RNA-binding proteins involved in post-transcriptional regulation in bacteria. Front Microbiol. 2015;6:141.

101. Chao Y, Vogel J. The role of Hfq in bacterial pathogens. Curr Opin Microbiol. 2010;13(1):24-33. 
102. Oaks JL, Besser TE, Walk ST, Gordon DM, Beckmen KB, Burek KA, et al. Escherichia albertii in wild and domestic birds. Emerg Infect Dis. 2010;16(4):638-46.

103. Yu D, Ellis HM, Lee EC, Jenkins NA, Copeland NG, Court DL. An efficient recombination system for chromosome engineering in Escherichia coli. Proc Natl Acad Sci U S A. 2000;97(11):5978-83.

104. Posfai G, Koob MD, Kirkpatrick HA, Blattner FR. Versatile insertion plasmids for targeted genome manipulations in bacteria: isolation, deletion, and rescue of the pathogenicity island LEE of the Escherichia coli O157:H7 genome. J Bacteriol. 1997;179(13):4426-8.

Submit your next manuscript to BioMed Central and we will help you at every step:

- We accept pre-submission inquiries

- Our selector tool helps you to find the most relevant journal

- We provide round the clock customer support

- Convenient online submission

- Thorough peer review

- Inclusion in PubMed and all major indexing services

- Maximum visibility for your research

Submit your manuscript at www.biomedcentral.com/submit
Biomed Central 